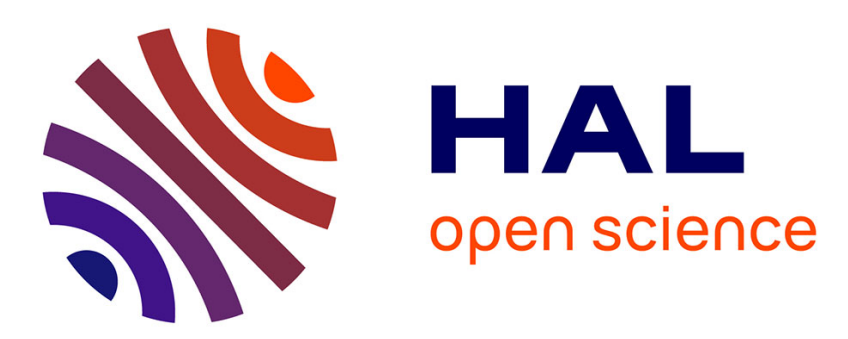

\title{
A microcracks-induced damage model for initially anisotropic rocks accounting for microcracks closure
}

\author{
Séverine Levasseur, Hélène Welemane, Djimédo Kondo
}

\section{To cite this version:}

Séverine Levasseur, Hélène Welemane, Djimédo Kondo. A microcracks-induced damage model for initially anisotropic rocks accounting for microcracks closure. International Journal of Rock Mechanics and Mining Sciences, 2015, vol. 77, pp. 122-132. 10.1016/j.ijrmms.2015.03.011 . hal-01212103

\section{HAL Id: hal-01212103 \\ https://hal.science/hal-01212103}

Submitted on 6 Oct 2015

HAL is a multi-disciplinary open access archive for the deposit and dissemination of scientific research documents, whether they are published or not. The documents may come from teaching and research institutions in France or abroad, or from public or private research centers.
L'archive ouverte pluridisciplinaire HAL, est destinée au dépôt et à la diffusion de documents scientifiques de niveau recherche, publiés ou non, émanant des établissements d'enseignement et de recherche français ou étrangers, des laboratoires publics ou privés. 


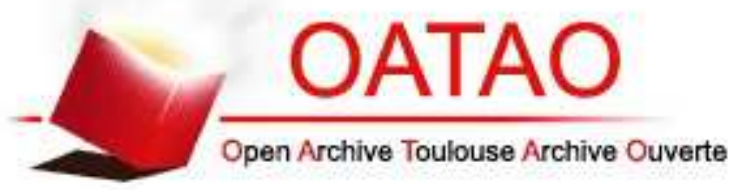

\section{Open Archive Toulouse Archive Ouverte (OATAO)}

OATAO is an open access repository that collects the work of Toulouse researchers and makes it freely available over the web where possible.

This is an author-deposited version published in: http://oatao.univ-toulouse.fr/ Eprints ID: 14221

To link to this article: DOI:10.1016/j.ijrmms.2015.03.011 http://dx.doi.org/10.1016/j.ijrmms.2015.03.011

\section{To cite this version:}

Levasseur, Séverine and Welemane, Hélène and Kondo, Djimédo $A$ microcracks-induced damage model for initially anisotropic rocks accounting for microcracks closure. (2015) International Journal of Rock Mechanics and Mining Sciences. Vol. 77. pp. 122-132. ISSN 1365-1609 


\title{
A microcracks-induced damage model for initially anisotropic rocks accounting for microcracks closure
}

\author{
S. Levasseur ${ }^{\mathrm{a}}$, H. Welemane ${ }^{\mathrm{b}}$, D. Kondo ${ }^{\mathrm{c}, *}$ \\ ${ }^{a}$ Université de Liège, dept. ArGEnCo, Chemin des chevreuils 1, 4000 Liège, Belgium \\ ${ }^{\mathrm{b}}$ Université de Toulouse, Ecole Nationale d'Ingénieurs de Tarbes - INP/ENIT EA 1905, 47 avenue d'Azereix, 65016 Tarbes, France \\ ${ }^{\mathrm{c}}$ Université de Paris VI, Institut d'Alembert, UMR CNRS 7190, 4 place Jussieu, 75005 Paris, France
}

Keywords:

Anisotropic rocks

Damage-induced anisotropy

Microcracks closure effects

Homogenization and micromechanics

Argillite

\begin{abstract}
A B S T R A C T
We formulate a new micromechanical damage model for anisotropic rocks. This model accounts not only for the coupling between material initial anisotropy and the damage-induced one, but also for the opening/closure status (the so-called unilateral effects) of evolving microcracks. A closed-form expression of the overall free energy of the microcracked medium is implemented in an appropriate thermodynamics framework to derive a complete damage model for initially anisotropic rocks. The salient features of this model are fully illustrated. Then, its capabilities are demonstrated through an application to a Taiwan argillite subjected to direct tensile loading (including off-axis ones) for which the damage model well captures experimental data (mechanical response, growing damage rocks strength). Finally, the response of the studied rock along a tensile loading followed by an unloading and a reloading in compression is provided in order to illustrate the so-called unilateral damage effects due to microcracks closure.
\end{abstract}

\section{Introduction}

The complex inelastic behavior of brittle rock-like materials under mechanical loading generally results from damage phenomena due to evolving microcracks. For the non-linear mechanical response of microcracked materials, Continuum Damage Mechanics (CDM, see, for instance, the textbooks of [1] and [2]) offers an appropriate theoretical framework. Since several decades, both phenomenological and micromechanical approaches of damage have been proposed. For continuum micromechanics, mention has to be made of several contributions dealing with effects of microcracking on materials properties (see, for instance, [3-6]). Formulation of isotropic or anisotropic damage by microcracks growth in rocks or concrete materials has been provided in several studies (see, for instance, [7-19]).

Despite their interest, the above cited models concern only materials which are initially isotropic (in their undamaged state). The purely macroscopic formulation of constitutive models coupling explicitly initial anisotropy and damage-induced one has been only investigated in few recent studies mainly devoted to brittle matrix composites; we refer here to Halm et al. [20] (see also [18] and [21]). Mention has also to be made of the purely macroscopic model for an initially anisotropic rock by Chen et al. [22]. Concerning micro-macro

\footnotetext{
* Corresponding author.

E-mail address: djimedo.kondo@upmc.fr (D. Kondo).
}

models, Baste et al. [23] and recently Monchiet et al. [24] proposed appropriate damage models which couple structural anisotropy and damage by microcracking. Yet, this class of models are limited to damage processes generated by open microcracks growth and need to be completed in order to properly account for microcracks closure. ${ }^{1}$ To this end, Goidescu et al. [25] recently established closed-form expressions of the overall free energy of orthotropic materials weakened by microcracks, either open or closed. The present study takes advantage of these very recent results in order to formulate a complete model which fully couples initially anisotropy and evolving unilateral damage due to 2D systems of open or closed microcracks under frictionless conditions.

The paper is organized as follows. We briefly recall the closed-form expression of the macroscopic free energy which will play in the present study the role of a thermodynamics potential for the damaged material. The state laws derived from this potential provide the macroscopic stress as well as the damage energy release rate (thermodynamic forces conjugated to damage) as a function of the macroscopic strain and the damage variables. By adopting a discrete damage representation defined by the microcracks density parameter, we then propose a damage yield function based on the damage energy release

\footnotetext{
${ }^{1}$ The corresponding unilateral effects are of paramount importance and necessary for quasi brittle geomaterials usually subjected to tensile loadings as well as compressive ones.
} 


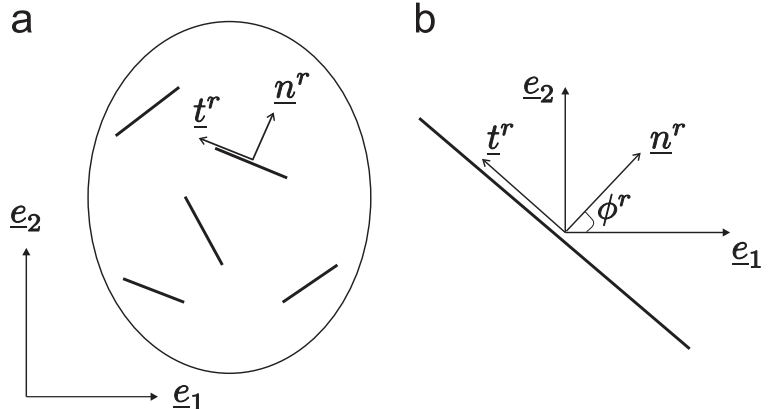

Fig. 1. (a) Representative volume element in 2D case; (b) crack coordinates system.

rate associated to each microcracks family. The corresponding damage surface is illustrated for various configurations of the microdefects system. Finally, we provide the damage evolution law by assuming normality rule and following classical thermodynamics-based procedure. This allows us to establish the complete rate formulation of the fully anisotropic constitutive damage law with account of microcracks closure. After a simple calibration step, the proposed model is assessed by comparing its prediction under tensile loading to available data on an argillite studied by Liao et al. [26]. Finally, the ability of the model to also account for microcracks closure effects is fully demonstrated in several cases.

Notations: Standard tensorial notations will be used throughout the paper. Lower underlined case letters will describe vectors, while bold script capital letters will be associated to second-order tensors and mathematical double-struck capital letters to fourth-order tensors. The following vector and tensor products are exemplified: $(\mathbf{A} \cdot b)_{i}=A_{i j} b_{j}, \quad(\mathbf{A} \cdot \mathbf{B})_{i j}=A_{i k} B_{k j}, \quad(\mathbb{A}: \mathbf{B})_{i j}=A_{i j k l} B_{k l}, \quad(\mathbb{A}: \mathbb{B})_{i j k l}=A_{i j p q}$ $B_{p q k l}, \quad(\mathbf{A} \otimes \mathbf{B})_{i j k l}=A_{i j} B_{k l} \quad$ and $(\mathbf{A} \otimes \mathbf{B})_{i j k l}=\frac{1}{2}\left(A_{i k} B_{j l}+A_{i l} B_{j k}\right)$. Einstein summation convention applied for the repeated indices and Cartesian coordinates are used. As usual, in the context of continuum micromechanics, small (respectively large) characters refer to microscopic (resp. macroscopic) quantities. I and $\mathbb{\square}$ are, respectively, the second and fourth order identity tensors, the components of the former are represented by the Kronecker symbol $\left(\delta_{i j}\right)$ while for the latter one has $I_{i j k l}=(1 / 2)\left(\delta_{i k} \delta_{j l}+\delta_{i l} \delta_{j k}\right)$.

\section{Overall free energy of a 2D anisotropic medium weakened by an arbitrarily oriented system of microcracks}

\subsection{Representative volume element (r.v.e.)}

Micromechanical formulation of a brittle damage model requires first the determination of the effective properties of the microcracked material by using an homogenization procedure.

Let us consider a representative volume element r.v.e. $\Omega$ of the material (see Fig. 1(a)); this is constituted of an elastic orthotropic solid matrix $s$ (with stiffness tensor $\mathbb{C}^{s}$ and occupying a domain $\Omega^{s}$ ) and an arbitrarily oriented system of flat microcracks families (denoted $r$ and occupying a domain $\Omega^{r}$ ). The latter are assumed open or frictionless closed, non-interacting and in dilute concentration. This assumption allows us to fully develop a proper representation of the anisotropic multilinear response of weakened materials and provides basic solutions for future developments related to more complex configurations (including for instance interactions between microcracks ${ }^{2}$ ). Microcracks of the $r^{\text {th }}$ family are characterized by their normal $n^{r}$ and tangent $t^{r}$ unit vectors, mean length $2 l^{r}$ (the corresponding crack

\footnotetext{
2 This could be done for instance by considering a Mori-Tanaka like homogenization scheme.
}

density is defined as $d^{r}=\mathcal{N}^{r}\left(l^{r}\right)^{2}$ in which $\mathcal{N}^{r}$ is the number of microcracks of this family per unit surface, see [3]).

This r.v.e. can be subjected either to uniform strain or uniform stress boundary conditions; the latter can take the form:

$\boldsymbol{\sigma}(\underline{z}) \cdot \underline{v}(\underline{z})=\boldsymbol{\Sigma} \cdot \underline{v}(\underline{z}), \quad \forall \underline{z} \in \partial \Omega$

in which $\boldsymbol{\sigma}$ denotes the microscopic stress field, $\boldsymbol{\Sigma}$ the macroscopic stress, $v$ the outward unit normal to $\partial \Omega$ and $z$ the vector position.

Let us recall that the present study deals with orthotropic materials weakened by arbitrarily oriented microcracks. The symmetry axes of the matrix correspond to an orthonormal basis $\left(\underline{e}_{1}, \underline{e}_{2}\right)$ (see Fig. 1) and its stiffness is given by

$\mathbb{C}^{s}=a_{1} \mathbf{I} \otimes \mathbf{I}+a_{2} \mathbf{I} \otimes \mathbf{I}+a_{3} \mathbf{A} \otimes \mathbf{A}+a_{4}(\mathbf{A} \otimes \mathbf{I}+\mathbf{I} \otimes \mathbf{A})$

in which $\mathbf{A}=\underline{e}_{1} \otimes \underline{e}_{1}$ denotes the structural fabric tensor and where

$a_{1}=\mathbb{C}_{2222}^{s}-2 \mathbb{C}_{1212}^{s}, \quad a_{2}=2 \mathbb{C}_{1212}^{s}$

$a_{3}=\mathbb{C}_{1111}^{s}+\mathbb{C}_{2222}^{s}-2 \mathbb{C}_{1122}^{s}-4 \mathbb{C}_{1212}^{s}$,

$a_{4}=\mathbb{C}_{1122}^{s}-\mathbb{C}_{2222}^{s}+2 \mathbb{C}_{1212}^{s}$

and

$\mathbb{C}_{1111}^{s}=\frac{E_{1}}{1-\nu_{12} \nu_{21}}, \quad \mathbb{C}_{2222}^{s}=\frac{E_{2}}{1-\nu_{12} \nu_{21}}$,

$\mathbb{C}_{1212}^{S}=G_{12}, \quad \mathbb{C}_{1122}^{S}=\mathbb{C}_{2211}^{S}=\frac{\nu_{21} E_{1}}{1-\nu_{12} \nu_{21}}$

$E_{1}$ and $E_{2}$ are the Young moduli in the symmetry axes of the material (respectively to $\underline{e}_{1}$ and $\underline{e}_{2}$ ), $G_{12}$ is the shear modulus and $\nu_{12}$ and $\nu_{21}$ are Poisson ratios related to $\left(\underline{e}_{1}, \underline{e}_{2}\right)$ (Poisson ratios verify the relation: $\left.E_{1} / \nu_{12}=E_{2} / \nu_{21}\right)$. Equivalently, the compliance $\mathbb{S}^{S}=\left(\mathbb{C}^{S}\right)^{-1}$ of the matrix is defined as follows in the principal basis $\left(\underline{e}_{1}, \underline{e}_{2}\right)$ according to the Voigt notation:

$\mathbb{S}^{S}=\left(\begin{array}{ccc}\frac{1}{E_{1}} & -\frac{\nu_{21}}{E_{2}} & 0 \\ -\frac{\nu_{12}}{E_{1}} & \frac{1}{E_{2}} & 0 \\ 0 & 0 & \frac{1}{G_{12}}\end{array}\right)_{\left(\underline{e}_{1}, \underline{e}_{2}\right)}$.

2.2. Thermodynamics potential of the anisotropic medium weakened by an arbitrarily oriented distribution of microcracks

The main homogenization procedure has been carried out by Goidescu et al. [25] who performed a direct microfractures mechanicsbased analysis of the anisotropic damaged materials, in the spirit of the studies done in the context of isotropic matrix by [4,6,7,15-17] and others. The macroscopic thermodynamic potential of the anisotropic medium weakened by an arbitrarily oriented distribution of microcracks is then obtained as a function of the macroscopic strain tensor $\mathbf{E}$ (the observable state variable) and of the set of damage variables $d^{r}$ (the internal state variables of the problem), noted $\underline{d}$, and associated to all microcracks family $r$ ranging from 1 to $N=\overline{N_{o}}+N_{c}$. Assuming a dilute concentration of microcracks, the solution of the homogenization problem comes to sum up the contributions of each family of parallel microcracks, namely

$$
\begin{aligned}
\Psi(\mathbf{E}, \underline{d})= & \frac{1}{2} \mathbf{E}: \mathbb{C}^{s}: \mathbf{E} \\
& -\sum_{r=1}^{N_{o}} d^{r}\left\{H_{n n}^{r}\left(\mathbf{N}^{r}: \mathbf{E}\right)^{2}+2 H_{n t}^{r}\left(\mathbf{N}^{r}: \mathbf{E}\right)\left(\mathbf{T}^{r}: \mathbf{E}\right)+H_{t t}^{r}\left(\mathbf{T}^{r}: \mathbf{E}\right)^{2}\right\} \\
& +\sum_{r=1}^{N_{c}} \frac{d^{r}}{H_{n n}^{r} H_{t t}^{r}-H_{n t}^{r^{2}}}\left\{\begin{array}{l}
H_{n n}^{r} H_{n t}^{r^{2}}\left(\mathbf{N}^{r}: \mathbf{E}\right)^{2}+2 H_{n t}^{r^{3}}\left(\mathbf{N}^{r}: \mathbf{E}\right)\left(\mathbf{T}^{r}: \mathbf{E}\right) \\
+H_{t t}^{r}\left(2 H_{n t}^{r^{2}}-H_{n n}^{r} H_{t t}^{r}\right)\left(\mathbf{T}^{r}: \mathbf{E}\right)^{2}
\end{array}\right\}
\end{aligned}
$$

where $N_{o}$ represents the number of open microcracks family and $N_{c}$ the number of closed cracks. One has $\mathbf{N}^{r}=\mathbb{C}^{s}:\left(\underline{n}^{r} \otimes \underline{n}^{r}\right)$ and 
$\mathbf{T}^{r}=\frac{1}{2} \mathbb{C}^{s}:\left(\underline{n}^{r} \otimes \underline{t}^{r}+\underline{t}^{r} \otimes \underline{n}^{r}\right)$ two second order symmetric tensors, $H_{n n}^{r}, H_{n t}^{r}$ and $H_{t t}^{r^{-}}$are scalar parameters that depend on the matrix properties and on the crack orientation $\phi^{r}=\left(\underline{e}_{1}, \underline{n}^{r}\right)$ (see Fig. 1) defined by

$H_{n n}^{r}=C\left(1-D \cos 2 \phi^{r}\right), \quad H_{n t}^{r}=C D \sin 2 \phi^{r}, \quad H_{t t}^{r}=C\left(1+D \cos 2 \phi^{r}\right)$

with scalars $C$ and $D$ being related to the initial stiffness components:

$C=\frac{\pi}{4} \frac{\sqrt{\mathbb{C}_{1111}^{s}}+\sqrt{\mathbb{C}_{2222}^{s}}}{\sqrt{\mathbb{C}_{1111}^{s} \mathbb{C}_{2222}^{s}-\left(\mathbb{C}_{1122}^{s}\right)^{2}}} \sqrt{\frac{1}{\mathbb{C}_{1212}^{s}}+2 \frac{\sqrt{\mathbb{C}_{1111}^{s} \mathbb{C}_{2222}^{s}-\mathbb{C}_{1122}^{s}}}{\mathbb{C}_{1111}^{s} \mathbb{C}_{2222}^{s}-\left(\mathbb{C}_{1122}^{s}\right)^{2}}}$

$D=\frac{\sqrt{\mathbb{C}_{1111}^{s}}-\sqrt{\mathbb{C}_{2222}^{s}}}{\sqrt{\mathbb{C}_{1111}^{s}}+\sqrt{\mathbb{C}_{2222}^{s}}}$

The transition between open and closed cracks is described by the criterion function $g$ (see [25]):

$g\left(\mathbf{E}, \underline{n}^{r}\right)=H_{n n}^{r} \mathbf{N}^{r}: \mathbf{E}+H_{n t}^{r} \mathbf{T}^{r}: \mathbf{E}$

If $g\left(\mathbf{E}, n^{r}\right)>0$ microcracks are open, while they are closed if not.

Note that the above formulation (6) can also be written in the following form:

$\Psi(\mathbf{E}, \underline{d})=\frac{1}{2} \mathbf{E}: \mathbb{C}^{\text {hom }}: \mathbf{E}$

with

$\mathbb{C}^{\text {hom }}=\mathbb{C}^{s}-\sum_{r=1}^{N} 2 d^{r} \mathbb{B}^{r}$

and

$\mathbb{B}^{r}=\mathcal{C}_{1}^{r} \mathbf{N}^{r} \otimes \mathbf{N}^{r}+\mathcal{C}_{2}^{r}\left[\mathbf{N}^{r} \otimes \mathbf{T}^{r}+\mathbf{T}^{r} \otimes \mathbf{N}^{r}\right]+\mathcal{C}_{3}^{r} \mathbf{T}^{r} \otimes \mathbf{T}^{r}$

Scalar $\mathcal{C}_{1}^{r}, \mathcal{C}_{2}^{r}$ and $\mathcal{C}_{3}^{r}$ are defined in case of open cracks (index o) as

$\mathcal{C}_{1_{0}}^{r}=H_{n n}^{r}, \quad \mathcal{C}_{2_{o}}^{r}=H_{n t}^{r}, \quad \mathcal{C}_{3_{0}}^{r}=H_{t t}^{r}$

while for closed cracks (index $c$ ) one has

$\mathcal{C}_{1_{c}}^{r}=-\frac{H_{n n}^{r} H_{n t}^{r^{2}}}{H_{n n}^{r} H_{t t}^{r}-H_{n t}^{r^{2}}}, \quad \mathcal{C}_{2_{c}}^{r}=-\frac{H_{n t}^{r^{3}}}{H_{n n}^{r} H_{t t}^{r}-H_{n t}^{r^{2}}}$,

$\mathcal{C}_{3_{c}}^{r}=-\frac{H_{t t}^{r}\left(2 H_{n t}^{r^{2}}-H_{n n}^{r} H_{t t}^{r}\right)}{H_{n n}^{r} H_{t t}^{r}-H_{n t}^{r^{2}}}$

From Eq. (10), the first state law which gives the macroscopic stress tensor $\boldsymbol{\Sigma}$ can be obtained by derivation:

$\boldsymbol{\Sigma}=\frac{\partial \Psi}{\partial \mathbf{E}}=\mathbb{C}^{\text {hom }}: \mathbf{E}$

With $\mathbb{B}^{r}$ being defined by (12), the second state law provides the expression of the damage energy release rate $F^{d^{r}}$ (derivative of $\Psi$ with respect to $d^{r}$ ):

$F^{d^{r}}=-\frac{\partial \Psi}{\partial d^{r}}=\mathbf{E}: \mathbb{B}^{r}: \mathbf{E}$

Note that the homogenized stiffness tensor $\mathbb{C}^{\text {hom }}$ and the damage energy release rate $F^{d^{r}}$ are both affected by the anisotropic properties of the solid matrix and also depend on the orientation of the considered microcracks family and on its opening-closure state. This is at the origin of the complex behavior which results from the coupling between initial anisotropy, damage-induced one and unilateral behavior as already discussed in Goidescu et al. [25].

\subsection{Damage yield function and its illustration}

We aim now at formulating the damage evolution laws. To this end, based on the classical thermodynamics arguments, we introduce the following form for the damage criterion associated to each family of microcracks:

$f^{r}\left(F^{d^{r}}, d^{r}\right)=F^{d^{r}}-\mathcal{R}\left(d^{r}\right)=0$

The scalar function $\mathcal{R}\left(d^{r}\right)$ represents the resistance to the damage evolution by microcracks growth. A classical choice for brittle damage in the context of an isotropic matrix (see, for instance, [27]), adopted in the present study, consists in (see, for instance, [28])

$\mathcal{R}\left(d^{r}\right)=\mathcal{K}+\xi d^{r}$

Following then an idea used for geomaterials by Pietruszczak et al. [29] who introduce a dependency of failure criterion with off-axis, it is proposed to adopt a dependence of the initial threshold with loading orientation $\psi$ :

$\mathcal{K}=\mathcal{K}_{0} \exp (\omega \psi)$

$\mathcal{K}_{0}, \omega$ and $\xi$ are material parameters relative to initial threshold and its evolution with damage; $\psi$ corresponds to the angle between orthotropy axis $e_{1}$ and macroscopic stress principal direction. The exponential term allows us to shift the yield surface from $\mathcal{K}_{0}$ according to the load direction. From (16), it is seen that the damage yield function for each microcracks family $r, f^{r}\left(F^{d^{r}}, d^{r}\right)=0$, is strongly sensitive to matrix anisotropy, microcrack orientation and their opening-closure state. Once the yield surface is reached, the microcracks density parameter $d^{r}$ will increase as described in (2.4).

To illustrate the overall shape of criterion (17), Figs. 2-5 show for different microcracks orientation $\phi^{r}$ the initial yield surface (virgin state, $\left.d_{0}^{r}=0\right)$ in the macroscopic strain spaces $\left(E_{22}, E_{11}\right)$, $\left(E_{11}, E_{12}\right)$ and $\left(E_{22}, E_{12}\right)$ associated to the axes of orthotropy $\left(\mathbf{E}=E_{11} \underline{e}_{1} \otimes \underline{e}_{1}+E_{12}\left(\underline{e}_{1} \otimes \underline{e}_{2}+\underline{e}_{2} \otimes \underline{e}_{1}\right)+E_{22} \underline{e}_{2} \otimes \underline{e}_{2}\right) ;$ for simplicity, only the source term of $\mathcal{K}$ is considered $(\omega=0$; $\mathcal{K}=\mathcal{K}_{0}=1.2 \mathrm{~kJ} / \mathrm{m}^{2}$ ). Moduli and Poisson ratio are similar to the one given in Table 1, no initial damage is considered. Various applications of the complete damage model to an anisotropic rock will be presented in Section 3.

Regarding these results, several general comments can be done. First, from the mathematical point of view, the thermodynamics potential $\Psi$ is of class $C^{\infty}$ on restricted strain space domains related respectively to open and closed microcracks (that is for states E such that $g\left(E, n^{r}\right)>0$ and $g\left(E, n^{r}\right)<0$ respectively) and of class $C^{1}$ on the global strain space (see analyses of [30] and [25]); this allows the definition of a different stiffness $\mathbb{C}^{\text {hom }}$ according to the microcracks status, while preserving the continuity of the macroscopic stress $\boldsymbol{\Sigma}$ and force $F^{d^{r}}$ at the transition between open and closed states; similar features can then be noted in Figs. 2-5 for the initial damage yield surface. Due to the dependence of $F^{d^{r}}$, the yield surface is always hyperbolic despite that it is affected by the state of microcracks; in particular, we note that the damage criterion $f\left(F^{d^{r}}, d^{r}\right)=0$ systematically exhibits a finite frontier in the open configuration of microcracks, contrary to the closed case; this shows the strong incidence of unilateral effects in the material response that will differ under tensile or compression loading regime, and also the more damaging capabilities of open microcracks configurations. Initial yield surface are represented in the strain spaces associated to the axes of orthotropy. In that case, the differences that can be observed between Figs. 2-5 come from the orientation of the microcracks with respect to the matrix anisotropy. In the particular case of a microcracks orientation of $\phi^{r}=45^{\circ}$, the difference between Fig. 4(b) and (c) clearly illustrates that this contribution on the yield surface is entirely induced by the amplitude of the matrix anisotropy. A similar remark can be done between Fig. 2(b) and (c) (and also between Fig. 5(b) and (c)) that are not completely symmetric due to the orthotropic elastic properties. 

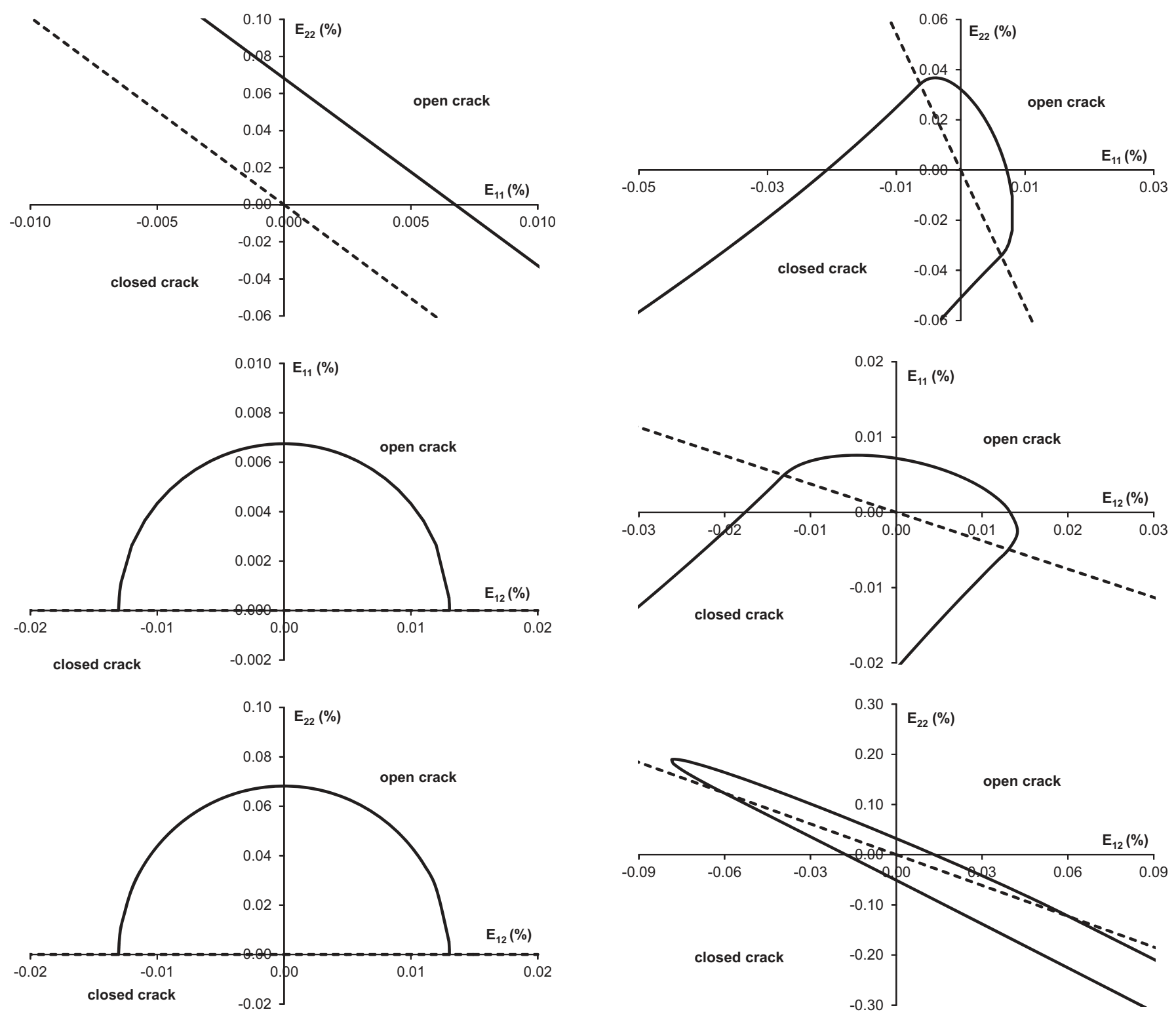

Fig. 2. Initial damage yield surface (virgin state, $\left.d_{0}^{r}=0\right)$ in the $\left(E_{22}, E_{11}\right),\left(E_{11}, E_{12}\right)$ and $\left(E_{22}, E_{12}\right)$ strain spaces for a microcrack orientation $\phi^{r}=0^{\circ}$ (dashed lines denote the hypersurface separating the open and closed microcracks domains).

2.4. Damage evolution law and rate form of the constitutive model

The damage evolution law is derived by using normality rule for a given family $r$ of microcracks:

$\dot{d}^{r}=\dot{\Lambda}^{r} \frac{\partial f^{r}}{\partial F^{d^{r}}}=\dot{\Lambda}^{r}$

where the damage multiplier $\dot{\Lambda}^{r}$ is deduced from the consistency condition:

$\dot{f}^{r}=\frac{\partial f^{r}}{\partial \mathbf{E}}: \dot{\mathbf{E}}+\frac{\partial f^{r}}{\partial d^{r}} \dot{d}^{r}=0$

It follows the damage evolution in the form:

$\dot{d}^{r}=\frac{1}{\xi} \dot{F}^{d^{r}}=\frac{2}{\xi} \mathbf{E}: \mathbb{B}^{r}: \dot{\mathbf{E}}$.

with the tensor $\mathbb{B}^{r}$ being defined by (12). Finally, by differentiating the macroscopic stress-strain relation given by (15), the macroscopic
Fig. 3. Initial damage yield surface (virgin state, $\left.d_{0}^{r}=0\right)$ in the $\left(E_{22}, E_{11}\right),\left(E_{11}, E_{12}\right)$ and $\left(E_{22}, E_{12}\right)$ strain spaces for a microcrack orientation $\phi^{r}=20^{\circ}$ (dashed lines denote the hypersurface separating the open and closed microcracks domains).

stress increment is expressed as

$\dot{\boldsymbol{\Sigma}}=\frac{\partial \boldsymbol{\Sigma}}{\partial \mathbf{E}} \dot{\mathbf{E}}+\sum_{r=1}^{N} \frac{\partial \boldsymbol{\Sigma}}{\partial d^{r}} \dot{d}^{r}=\mathbb{C}_{t}^{h o m}: \dot{\mathbf{E}}$

with the tangent operator

$\mathbb{C}_{t}^{\text {hom }}=\mathbb{C}^{\text {hom }}-\frac{1}{c_{1}} \mathbf{E}:\left(\sum_{r=1}^{N} \mathbb{B}^{r} \otimes \mathbb{B}^{r}\right): \mathbf{E}$

\subsection{Integration in a finite element code of the micromechanical model}

Even the applications shown in the present study do not necessarily require finite element computations, for further numerical simulations, the micromechanical damage model has been implemented in the (finite element) code LAGAMINE developed by the University of Liège since the 1980s (with [31,32]). The algorithm of local integration is based on an incremental procedure associated with the rate form of 

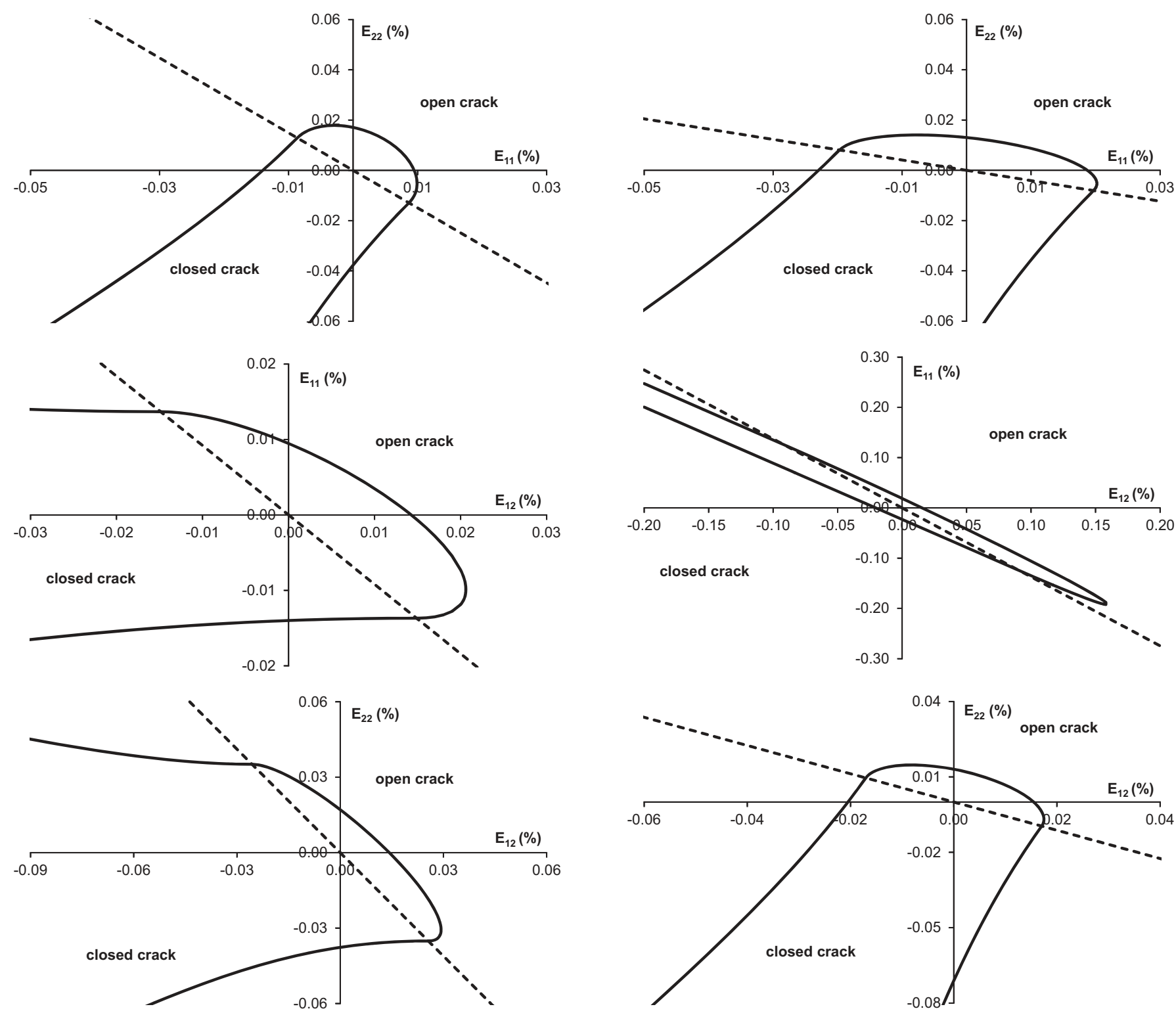

Fig. 4. Initial damage yield surface (virgin state, $\left.d_{0}^{r}=0\right)$ in the $\left(E_{22}, E_{11}\right),\left(E_{11}, E_{12}\right)$ and $\left(E_{22}, E_{12}\right)$ strain spaces for a microcrack orientation $\phi^{r}=45^{\circ}$ (dashed lines denote the hypersurface separating the open and closed microcracks domains).

stress-strain relation and the strain discretization of the loading path. The scheme for the step $j$ to $j+1$ begins with the initialization of strain tensor and state variables by applying a strain increment $\Delta \mathbf{E}_{j+1}$ :

$\left\{\begin{array}{l}\mathbf{E}_{j+1}=\mathbf{E}_{j}+\Delta \mathbf{E}_{j+1} \\ d_{j+1}^{r}=d_{j}^{r}, \quad \forall r=1, \ldots, N\end{array}\right.$

Fig. 5. Initial damage yield surface (virgin state, $\left.d_{0}^{r}=0\right)$ in the $\left(E_{22}, E_{11}\right),\left(E_{11}, E_{12}\right)$ and $\left(E_{22}, E_{12}\right)$ strain spaces for a microcrack orientation $\phi^{r}=70^{\circ}$ (dashed lines denote the hypersurface separating the open and closed microcracks domains).

Table 1

Model parameters for the Taiwan argillite.

\begin{tabular}{lllllll}
\hline$E_{1}$ & $E_{2}$ & $\nu_{12}$ & $G_{12}$ & $\mathcal{K}_{0}$ & $\omega$ & $\xi$ \\
\hline $60 \mathrm{GPa}$ & $27 \mathrm{GPa}$ & 0.22 & $13 \mathrm{GPa}$ & $0.2 \mathrm{~kJ} / \mathrm{m}^{2}$ & 0.043 & $10 \mathrm{~kJ} / \mathrm{m}^{2}$ \\
\hline
\end{tabular}

Then, for $r=1, \ldots, N$, the opening-closure condition is examined:

$g\left(\mathbf{E}, \underline{n}^{r}\right)=H_{n n}^{r} \mathbf{N}^{r}: \mathbf{E}+H_{n t}^{r} \mathbf{T}^{r}: \mathbf{E}$

For $r=1, \ldots, N$, damage criterion $f\left(F^{d_{j}^{r}}, d_{j}^{r}\right)$ from Eq. (17) has to be evaluated with appropriate $\mathcal{C}_{1}^{r}, \mathcal{C}_{2}^{r}$ and $\mathcal{C}_{3}^{r}$ constants defined by (13) for open microcracks $\left(g\left(\mathbf{E}, \underline{n}^{r}\right)>0\right)$ and (14) for closed microcracks $\left(g\left(\mathbf{E}, \underline{n}^{r}\right) \leq 0\right)$ : if $f\left(F^{d_{j}^{r}}, d_{j}^{r}\right)<0$ then $d_{j+1}^{r}=d_{j}^{r}$; if $f\left(F^{d_{j}^{r}}, d_{j}^{r}\right) \geq 0$ then one has to calculate $\Delta d_{j+1}^{r}$ using Eq. (22) and to update $d_{j+1}^{r}=d_{j}^{r}+\Delta d_{j+1}^{r}$. Finally, the macroscopic stress tensor $\boldsymbol{\Sigma}_{j+1}$ is updated from Eqs. (11) and (15), so as the tangent operator $\left(\mathbb{C}_{t}^{\text {hom }}\right)_{j+1}$ with Eq. (24).

\section{Applications and validation}

As a support for the validation of the new proposed damage model, we consider the anisotropic Taiwan argillite studied by Liao et al. [26]. This class of materials is commonly considered for underground excavation projects. The Taiwan argillite was formed from slight metamorphism of shale or silty shale. It is composed of about $45 \%$ of quartz and $55 \%$ clay minerals (illite, chloride for instance), its dry unit weight is about $27 \mathrm{kN} / \mathrm{m}^{3}$ with a very low porosity of about $0.014-0.018$. Clear foliation planes are well-developed by recrystallization of clay minerals. 


\subsection{Identification of the model}

Liao et al. [26] investigated the tensile response of such argillite under axis and off-axis loads by employing a servocontrolled material testing machine (model MTS 810) with tensile grip, which is a computer controlled machine with $250 \mathrm{kN}$ load capacity. Denoting $(\underline{x}, y)$ the orthonormal basis corresponding to the testing device frame, several uniaxial tests along $y$-axis have been performed for different loading orientations $\psi=\left(x, \bar{e}_{1}\right)=\left(y, e_{2}\right)$ with $\left(e_{1}, e_{2}\right)$ being the principal axes of this transversely isotropic rock (see Fig. 6). For each test, displacements have been measured by LVDT, strain by extensometer.

A plane strain approach is adopted for the modeling of the studied rock. Owing to symmetry considerations, only one quarter of the sample is considered. Vertical displacements are locked on the bottom $(y=0)$ and horizontal displacements are locked on the left side $(x=0)$. The tensile loading $\Sigma_{y y}$ is applied on the top of the sample (Fig. 6). All simulations are made by using for the damage representation a discretization of $N=60$ families of microcracks with uniform distribution of unit normals $\underline{n}^{r}$, that is $\phi^{r}=\left(\underline{e}_{1}, \underline{n}^{r}\right)=\pi(r-1) / N, \forall r=1,60$.

The four elastic constants can be determined from the linear part of the laboratory tests. $E_{1}$ is directly estimated from $\left(\Sigma_{y y}, E_{y y}\right)$ curve for the test at $\psi=90^{\circ} ; E_{2}$ is directly estimated from $\left(\Sigma_{y y}, E_{y y}\right)$ curve for the test at $\psi=0^{\circ} ; G_{12}$ and $\nu_{12}$ are calibrated to reproduce in average $\left(\Sigma_{y y}, E_{x x}\right)$ and $\left(\Sigma_{y y}, E_{y y}\right)$ curves for all the tests.

The experimental results clearly put also in evidence the dependence of the damage evolution with the orientation of foliation planes (Fig. 7). Especially, we note that stress-strain curves exhibit nonlinearity before failure for low inclination $\psi$, whereas the responses are quite linear for high inclination $\psi$. Considering an initial isotropic damage distribution (initial state such that $d_{0}^{r}=0.01, \forall r=1,60$ ), the two remaining model parameters have then been identified from the variation of the initial damage threshold with loading orientation that follows the exponential relation (19) with $\mathcal{K}_{0}=0.2 \mathrm{~kJ} / \mathrm{m}^{2}$ and $\omega=0.043$ (Fig. 8). The same evolution of damage is assumed for all the tests through the definition of the $\xi$ parameter of Eq. (18). Table 1 summarizes the results of the calibration procedure for the Taiwan argillite.

\subsection{Simulation of uniaxial tensile test on Taiwan argillite}

The results of the above model calibration are shown in Figs. 9 and 10. In addition to the overall response, the orientational average damage $\bar{d}=(1 / N) \sum_{r=1}^{N} d^{r}$, induced by the load, is also depicted. It is observed that the stress-strain curves $\Sigma_{y y}-E_{y y}$ and tensile strengths are well captured by the model (except maybe for the case $\psi=30^{\circ}$ for which experimental data seems less accurate); on the other hand, the predicted evolutions of the damage seem realistic. Especially, the model is able to capture the experimental trends that can be related to some transition with the change of the loading angle $\psi$. For the tensile loads, microcracks develop mainly along the normal

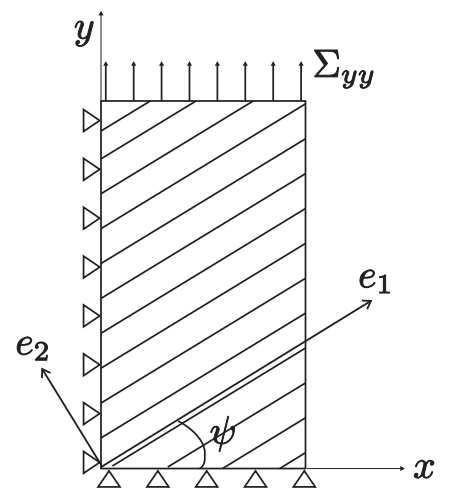

Fig. 6. Uniaxial tensile test and anisotropy orientation. a

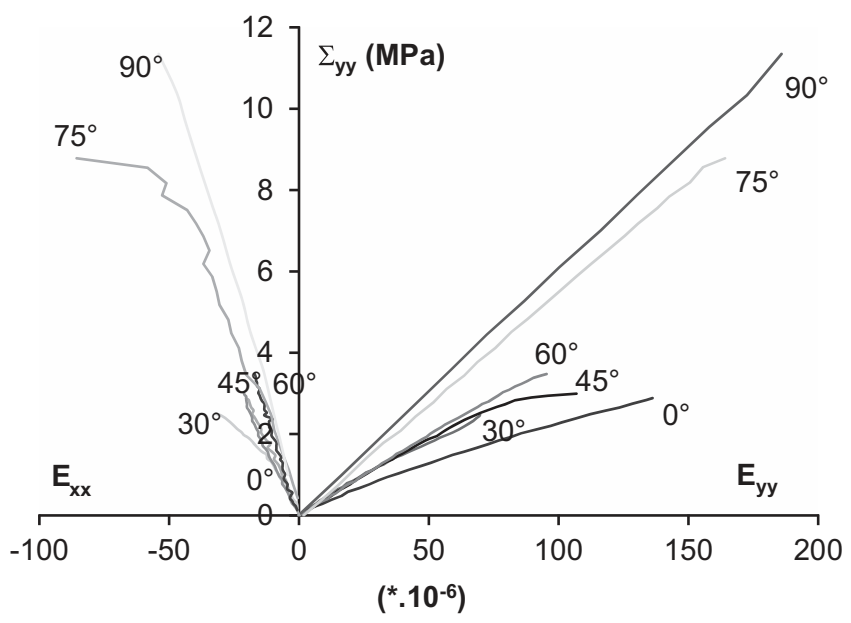

b

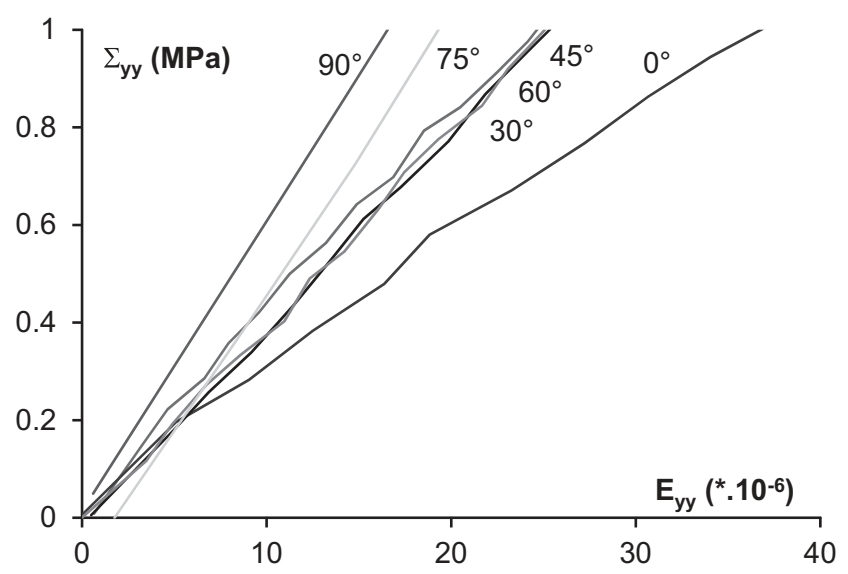

Fig. 7. Experimental stress-strains responses for different loading orientations $\psi=$ $0^{\circ}, 30^{\circ}, 45^{\circ}, 60^{\circ}, 75^{\circ}, 90^{\circ}\left(\Sigma_{y y}\right.$ the axial stress, $E_{y y}$ the axial strain, $E_{x x}$ the radial strain): (a) global response, (b) zoom on linear elastic part.

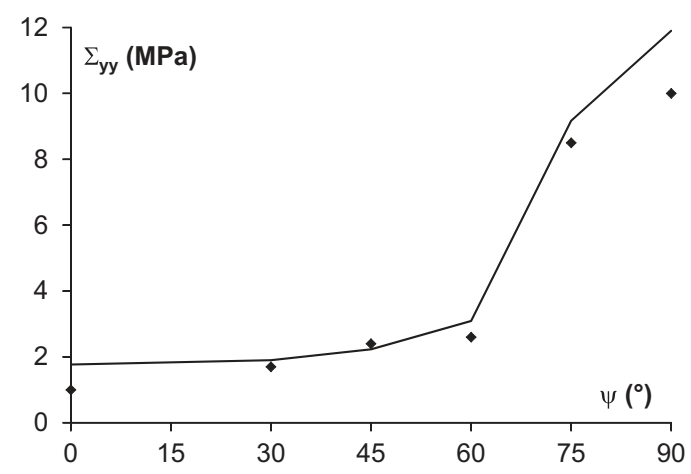

Fig. 8. Variation of axial stress $\Sigma_{y y}$ corresponding to the initial damage threshold with loading orientation $\psi$ : experimental results (symbols) and model calibration (full line).

direction to loading, so along $\underline{x}$-axis in our example; in other words, the orientation of the microcracks family with the highest density is $\phi^{r}=90^{\circ}$ when $\psi=0^{\circ}$. The theoretical approach provides a different interaction between initial anisotropy and damage induced one: for load with low inclination $\psi$, damage appears earlier and grow gradually causing a more pronounced non-linear behavior of argillite; on the contrary for high inclination, damage occurs later and its propagation is rather sudden. Numerically, the latter case leads rapidly 
a

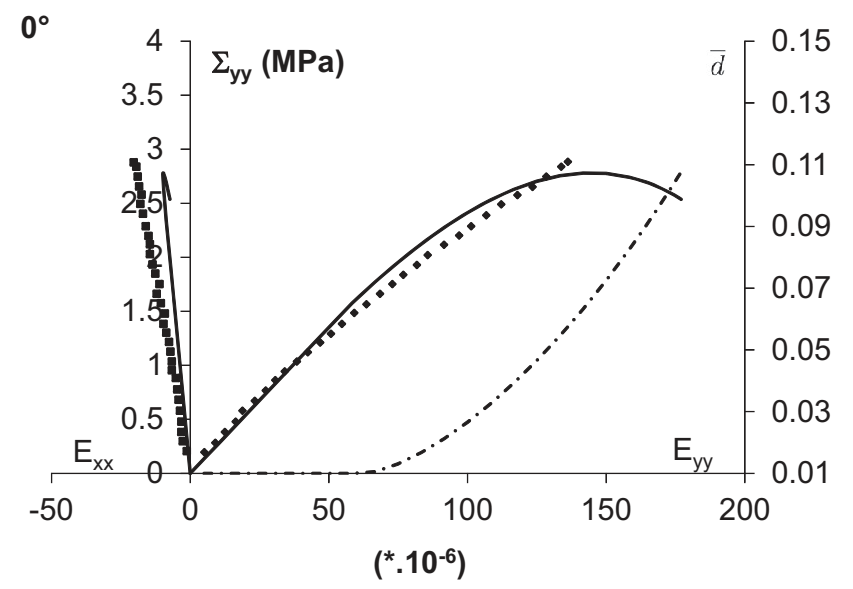

b

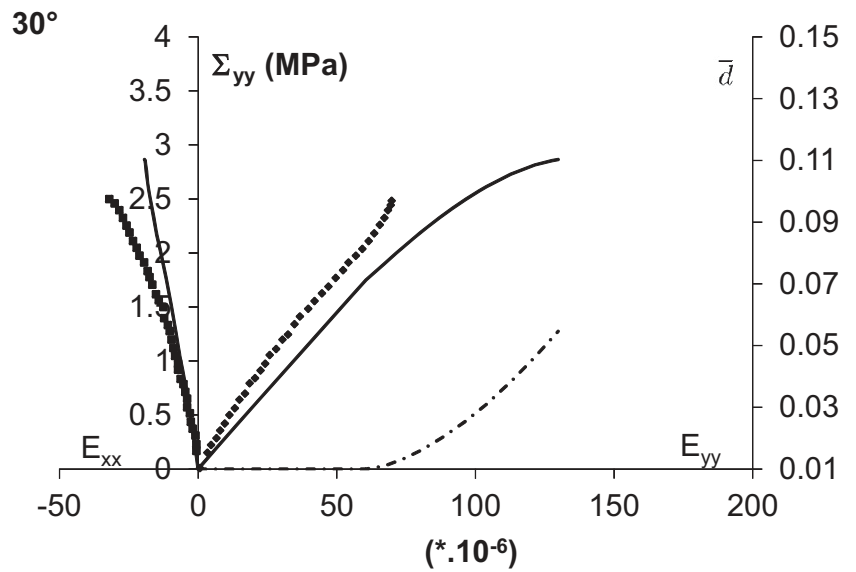

C

$45^{\circ}$

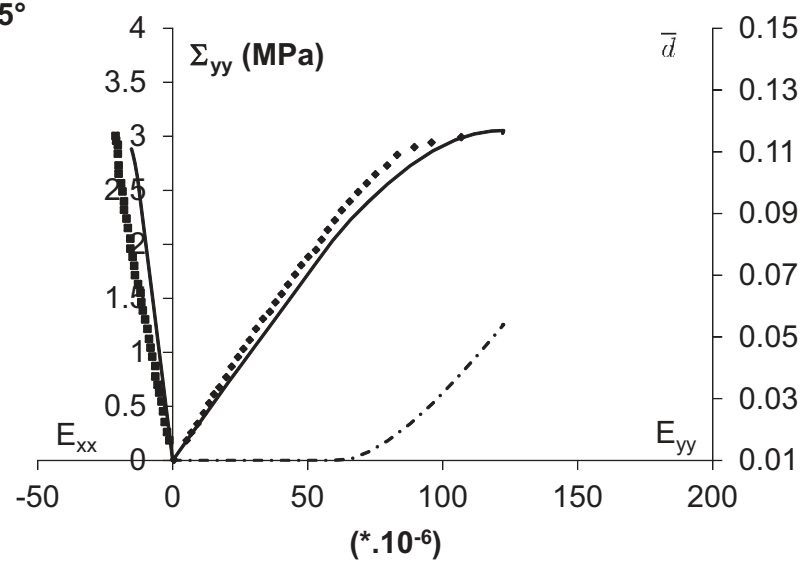

Fig. 9. Model predictions of the argillite stress-strain responses and mean damage for 3 loading axis orientations: (a) $\psi=0^{\circ}$, (b) $\psi=30^{\circ}$, (c) $\psi=45^{\circ}$ (symbols: lab measurements; full lines: stress-strain numerical results; dash lines: damage numerical results).

to the non-convergence of the model due to the strong damage levels reached.

By analogy to stress paths in elasto-plasticity theory, a "damage path" can be drawn in the strain space associated to orthotropy axes (Fig. 11). Two loading orientations $\psi$ have been considered; initial and final damage yield surfaces are also depicted as a reference, considering in each case one family of microcracks corresponding to the preferential orientation (maximum density) obtained under tensile loading (that is $\phi^{r}=90^{\circ}$ for $\psi=0^{\circ}$ and $\phi^{r}=45^{\circ}$ for $\psi=45^{\circ}$ ). Even a

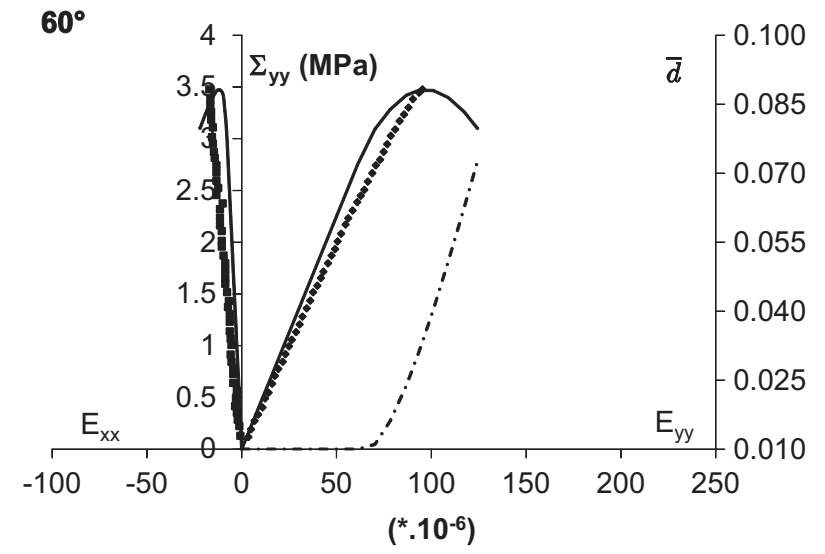

b
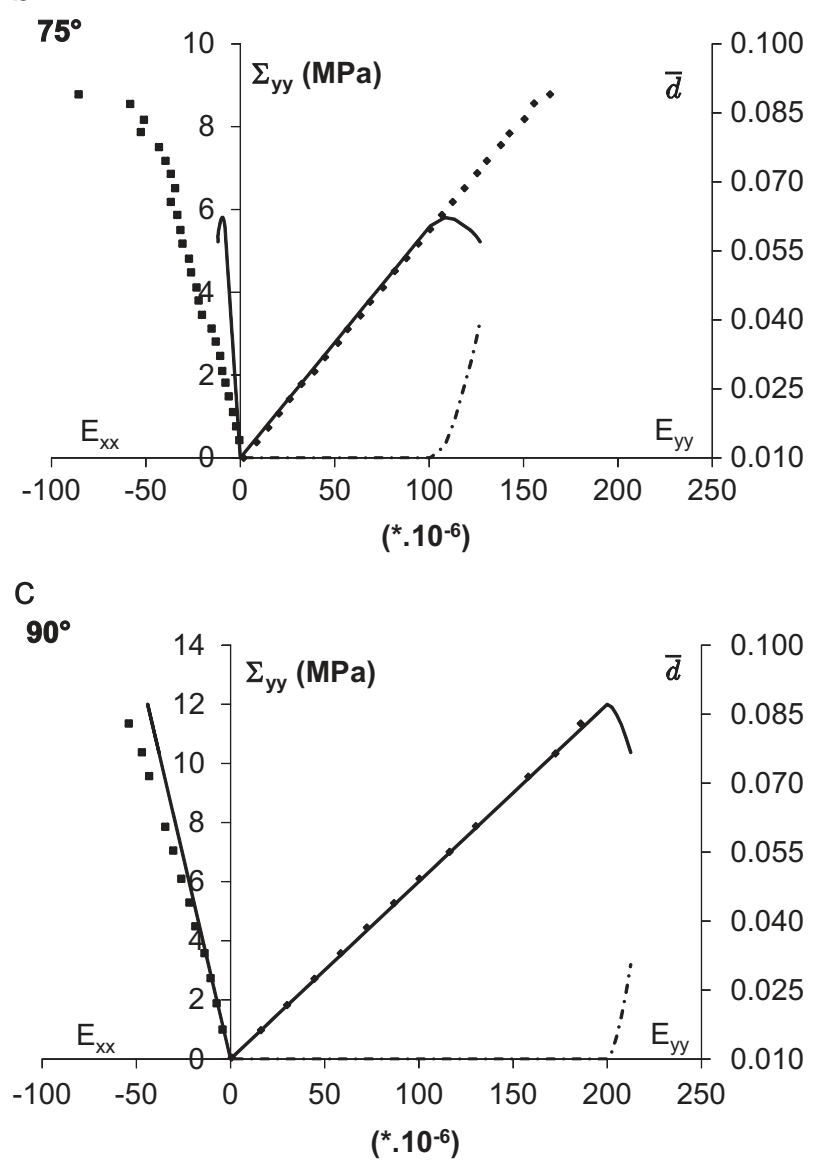

Fig. 10. Model predictions of the argillite stress-strain responses and mean damage for 3 loading axis orientations: (a) $\psi=60^{\circ}$, (b) $\psi=75^{\circ}$, (c) $\psi=90^{\circ}$ (symbols: lab measurements; full lines: stress-strain numerical results; dash lines: damage numerical results).

for elastic behavior, Fig. 11 clearly puts in evidence the differences between axis and off-axis loads induced in the initial principal strain space. It is also observed that microcracks remain in their open status for both tests. Also, once strain state reaches damage criterion in one direction, the damage criterion varies linearly with damage both in open and closed crack domains and similarly in all directions due to scalar resistance considered in Eq. (18). Consequently, the final damage surface is homothetic to the initial one.

Damage coupling with matrix anisotropy affects also the overall compliance tensor $\mathbb{S}^{\text {hom }}=\left(\mathbb{C}^{\text {hom }}\right)^{-1}$. Variations of the components of 
a

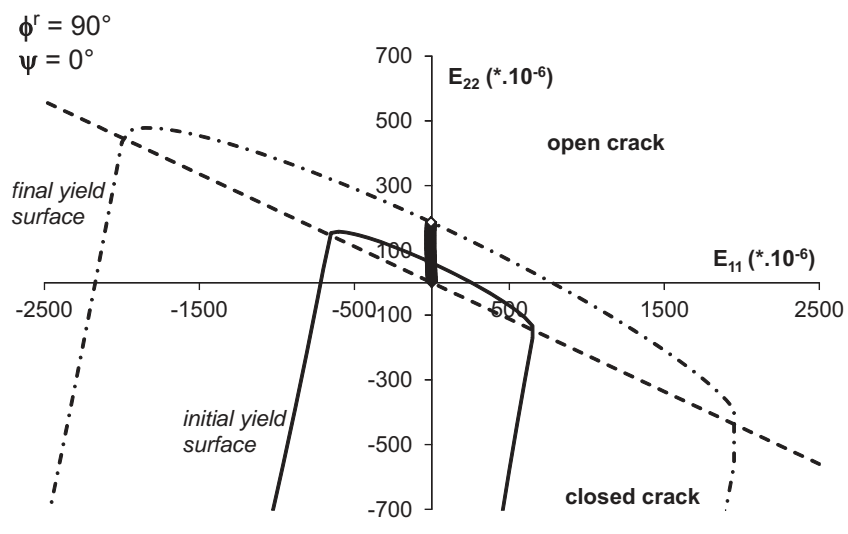

b

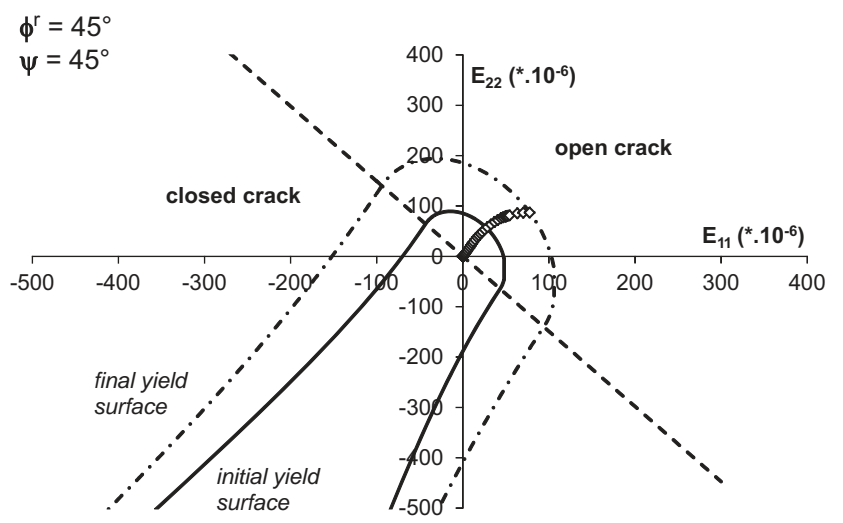

Fig. 11. Tensile loading path in $\left(E_{22}, E_{11}\right)$ orthotropic strain space (diamond symbols) for two loading orientations $\psi=0^{\circ}$ and $90^{\circ}$ with initial $\left(d_{0}^{r}=0.01\right.$, full lines) and final $\left(d^{r}\left(\psi=0^{\circ}\right)=0.15\right.$ and $d^{r}\left(\psi=45^{\circ}\right)=0.12$, dash lines) damage yield surfaces for the related preferential microcrack orientations: (a) axis-load: $\psi=0^{\circ}, \phi^{r}=90^{\circ}$, (b) off-axis load: $\psi=45^{\circ}, \phi^{r}=45^{\circ}$.

this tensor in the material basis $\left(\underline{e}_{1}, \underline{e}_{2}\right)$ of anisotropy and in the basis $(x, y)$ (Eq. (5)) associated to the loading are shown in Fig. 12 for two loading cases:

$$
\mathbb{S}^{\text {hom }}=\left(\begin{array}{lll}
S_{111}^{\text {hom }} & S_{1122}^{\text {hom }} & S_{1211}^{\text {hom }} \\
S_{1122}^{\text {hom }} & S_{2222}^{\text {hom }} & S_{1222}^{\text {hom }} \\
S_{1211}^{\text {hom }} & S_{1222}^{\text {hom }} & S_{1212}^{\text {hom }}
\end{array}\right)_{\left(\underline{e}_{1}, e_{2}\right)}=\left(\begin{array}{ccc}
S_{x x x x}^{\text {hom }} & S_{x x y y}^{\text {hom }} & S_{x y x x}^{\text {hom }} \\
S_{x x y y}^{\text {hom }} & S_{y y y y}^{\text {hom }} & S_{x y y y}^{\text {hom }} \\
S_{x y x x}^{\text {hom }} & S_{x y y y}^{\text {hom }} & S_{x y x y}^{\text {hom }}
\end{array}\right)_{(\underline{x}, \underline{y})}
$$

This figure shows that when $\psi=0^{\circ}$, microcracks evolve along bedding plane affecting mainly $S_{2222}^{\text {hom }}$ (or $S_{\text {yyyy }}^{\text {hom }}$ ) component of $\mathbb{S}^{\text {hom }}$ tensor. When $\psi=45^{\circ}$, microcracks still evolve along $x$-axis which is now different from the bedding plane. As a result, the evolution of $S_{2222}^{\text {hom }}$ (or $S_{y y y y}^{\text {hom }}$ ) component is quite similar for both loading orientations, whereas effects on $S_{1111}^{\text {hom }}$ and $S_{1212}^{\text {hom }}$ are more significant when $\psi=45^{\circ}$. However, in the basis $(x, y)$, the evolution of $S_{y y y y}^{\text {hom }}$ is more pronounced than the evolution of $S_{x x x x}^{\text {hom }}$ due to a strong coupling between matrix anisotropy and damage induced anisotropy (see Appendix). Note also that in case $\psi=45^{\circ}$, earlier non-convergence of the model is caused by an intense damage that occurs more suddenly (as already observed in Figs. 9 and 10).

To be more illustrative, let us examine the effective Young modulus $E^{\text {eff }}(\underline{v})$ defined for any direction of unit vector $\underline{v}$ by [33]:

$E^{e f f}(\underline{v})=\left[\underline{v} \otimes \underline{v}: \mathbb{S}^{\text {hom }}: \underline{v} \otimes \underline{v}\right]^{-1}$

Fig. 13 presents the distribution of such modulus normalized by its initial orthotropic value $E^{s}(\underline{v})$ (respectively derived for compliance a

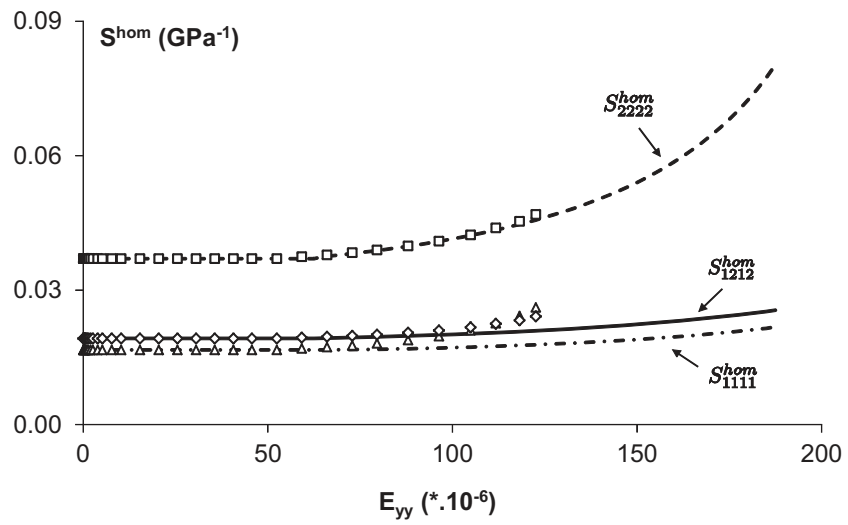

b

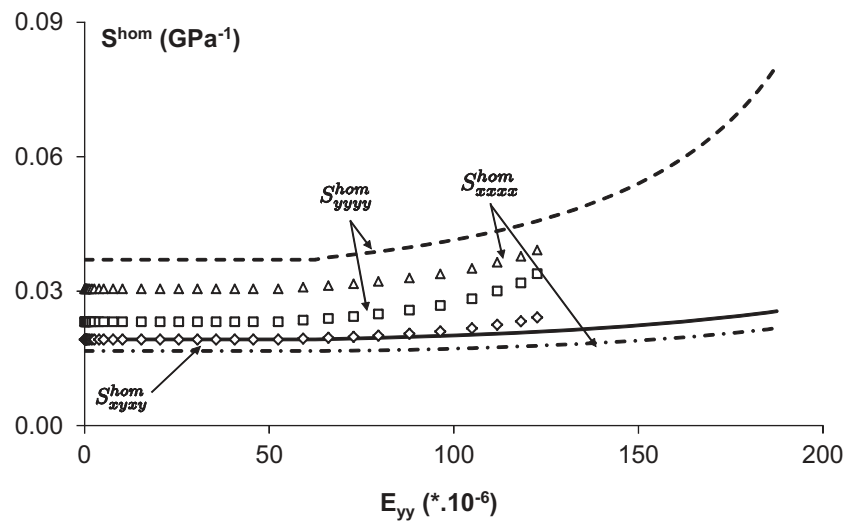

Fig. 12. Evolution of the components of the homogenized tensor $\mathbb{S}^{\text {hom }}$ in (a) anisotropic basis $\left(\underline{e}_{1}, \underline{e}_{2}\right)$ and (b) calculation basis $(\underline{x}, \underline{y})$ with axial strain: lines refer to $\psi=0^{\circ}$, symbols refer to $\psi=45^{\circ}$.

tensor $\mathbb{S}^{S}$ ) for the two studied loading cases; the initial values correspond to unit circles. When damage occurs, moduli are degraded. However, because of a strong coupling between matrix anisotropy and damage induced anisotropy, these degradations differ from one direction to the others. In case of $\psi=0^{\circ}$, loading direction corresponds to an initial principal axis; then, structural and induced anisotropies remain collinear. In case of $\psi=45^{\circ}$, loading direction does not correspond to the anisotropy axis, so we can observe the competition between initial anisotropy (with axes $\left.\left(\underline{e}_{1}, \underline{e}_{2}\right)\right)$ and induced anisotropy (with axes $(x, y))$ since microcracks mainly develop along axis $\underline{x}$.

\subsection{Microcracks closure effect: tension-compression loading}

In order to investigate microcracks closure effects on the macroscopic behavior, we consider that one has to perform the unilateral effect through the modeling of tensile loading followed by an unloading and then reloading in compression. The objective is to evaluate how progressive closure of open microcracks (initially generated during the tension loading step) affects the material response during the compression phase. Note that the response under tension loading is the same as described above.

Fig. 14 presents the axial stress-strain curve $\Sigma_{y y}-E_{y y}$ corresponding to the above tension-compression loading path for the axis case $\psi=0^{\circ}$. In the same figure, is provided the evolution of the average damage $\bar{d}$ with axial strain $E_{y y}$. The obtained stress-strain curve shows continuous response at the tension-compression transition (when axial stress is equal to zero corresponding to the opening/closure transition) despite the discontinuity of the macroscopic elastic properties at this transition. 

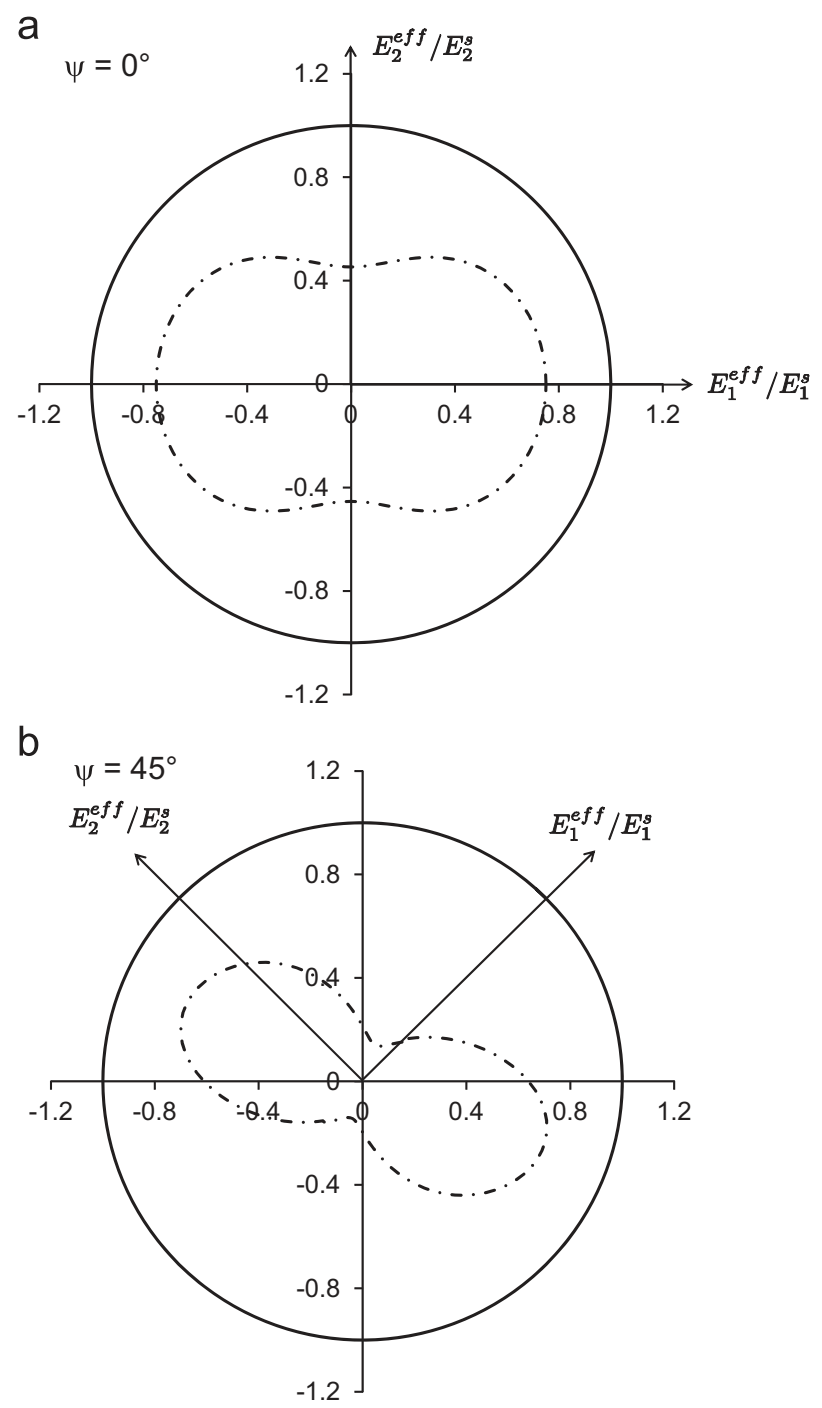

Fig. 13. Evolution of the distribution of the normalized effective Young modulus $E^{\text {eff }}(v) / E^{S}(v)$ : (a) axis-load: $\psi=0^{\circ}$, (b) off-axis load: $\psi=45^{\circ}$ (full lines: initial unit circle; dash lines: final distribution of normalized properties).

It has been noted that depending of the loading regime (tension or compression phase), microcracks do not grow in the same directions. Indeed, as indicated before, the preferential microcrack orientation during the first tensile phase is along axis $x$ (the family of cracks with orientation $\phi^{r}=90^{\circ}$ exhibits the maximum density). On the contrary, during compression reloading phase, the most evolved microcracks are oriented at about $\phi^{r}=45^{\circ}$ (see [28]). Furthermore, the status of these families differs according to the load (open during the tensile phase, closed during compression). Representation of the tensioncompression loading path in strain space with related preferential damage yield surfaces allows us to explain the different stages of damage (see Figs. 14 and 15). Naturally, as long as tensile loading does not reach damage criterion for the family of microcracks with $\phi^{r}=90^{\circ}$, damage is constant to initial isotropic value $d_{0}=0.01$ and stress-strain relation is linear; microcracks are all open in this case. After this yield surface is reached, damage evolves and generates the non-linearity of stress-strain curve due to the degradation of stiffness tensor. Moreover, the evolving damage induces growth of damage surface for the main microcracks family $\left(\phi^{r}=90^{\circ}\right)$. During unloading phase, the strain path comes into the elastic convex domain with a constant damage level. When compression load is applied, most of microcracks get closed (only few families with normal close to $x$ remain open, see [28]); this modification of the defects status induces

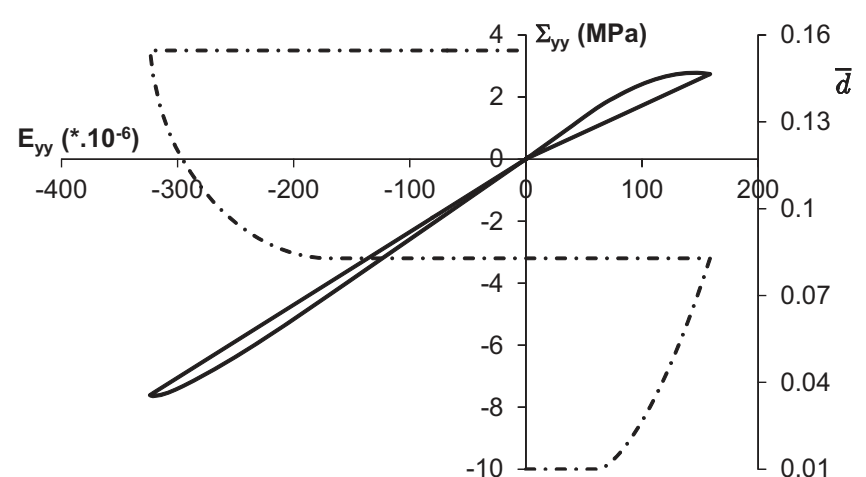

Fig. 14. Simulation of tensile loading followed by unloading and reloading in compression for axis loading $\left(\psi=0^{\circ}\right.$ ) (full line: axial stress-strain curve $\Sigma_{y y}-E_{y y}$; dashed line: evolution of mean damage $\bar{d}$ with axial strain).

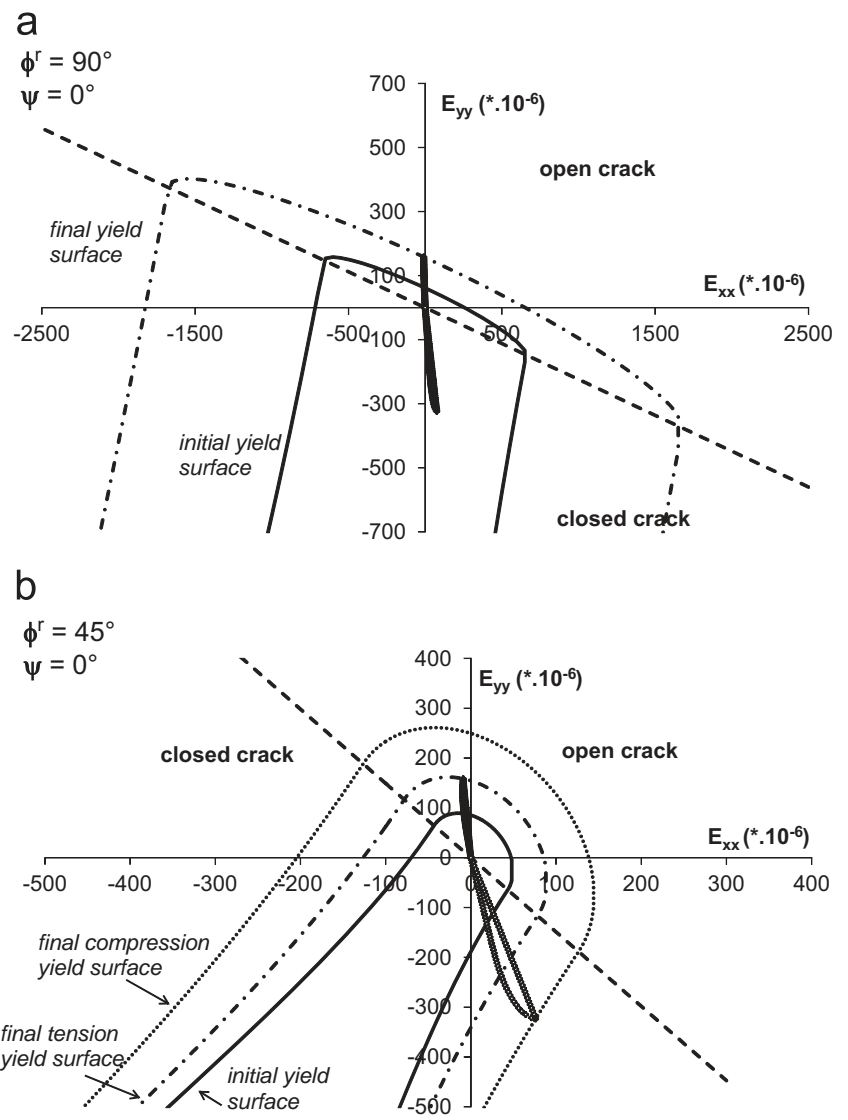

Fig. 15. Tensile unloading-compression loading path in $\left(E_{y y}, E_{x x}\right)$ strain space (diamond symbols) for axis load $\psi=0^{\circ}$ : initial $\left(d_{0}^{r}=0.01\right.$, full lines) and final (after tension load $d^{r}\left(\phi^{r}=90^{\circ}\right)=0.174$ and $d^{r}\left(\phi^{r}=45^{\circ}\right)=0.078$, dash lines; after compression load $d^{r}\left(\phi^{r}=90^{\circ}\right)=0.174$ and $d^{r}\left(\phi^{r}=45^{\circ}\right)=0.236$, dot lines) damage yield surfaces and opening-closure hypersurfaces for the related preferential microcrack orientation $\left((\mathrm{a}) \phi^{r}=90^{\circ}\right.$; (b) $\left.\phi^{r}=45^{\circ}\right)$.

a non-linearity (change of the overall elasticity) but without damage evolution as shown in Fig. 16 which displays the distributions of the normalized effective Young modulus and of the normalized damage $d^{r} / d_{0}^{r}$ after tensile loading and compression reloading. Damage evolves again when the path reaches the yield surface of the microcracks with orientation $\phi^{r}=45^{\circ}$ that are in the closed state. Note that similar results are obtained whatever the anisotropy orientation $\psi$. Even if such test has not been performed for now on the studied argillite, it should be underlined that predictions of the model stand in 

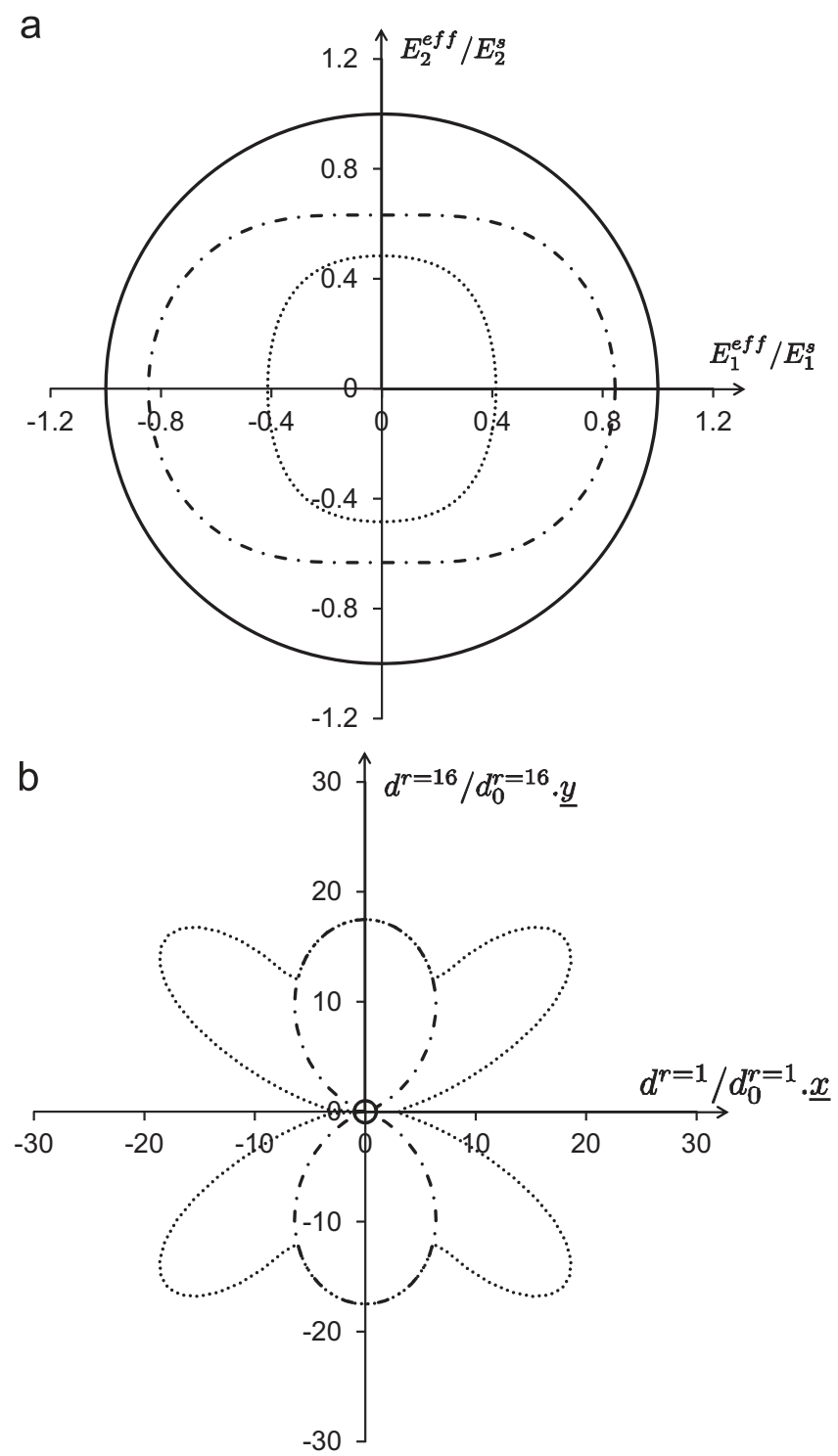

Fig. 16. Evolution of (a) the distribution of the normalized effective Young modulus $E^{\text {eff }}(v) / E^{S}(v)$ and (b) the distribution of the normalized damage $d^{r} / d_{0}^{r}$ after tensile loading (dash lines) and compression reloading (dot lines) (full lines refer to initial states - unit circles).

agreement with experimental tendencies obtained for a sandstone [34] or for concrete materials [35].

\section{Conclusions}

Taking advantage of the recent study by Goidescu et al. [25], a full 2D anisotropic micromechanical damage model has been formulated for initially anisotropic rocks. The originality of the formulation mainly lies in accounting for the coupling between the damage-induced anisotropy and the orthotropy of the solid matrix and in the characterization of unilateral effects of evolving microcracks. Applied to argillite, the model predicts that the initial anisotropy of the rock strongly affects the damage initiation and growth and subsequently the macroscopic response of the material through the stiffness degradation. Furthermore, depending of the orientation of the load with respect to the material symmetry axis, damage can occur gradually or suddenly, leading either to non-linear or to quasi-linear behavior of the studied argillite, as observed during experiments. Microcracks opening/closure effects are also illustrated through the material response under a tension-compression test. Moreover, the systematic analysis of the damage criterion in strain space provides an appropriate description of damage evolution process and the various coupling effects which accompanied it.

Further investigations need now to be conducted to complete the validation, especially regarding the comparison with experimental data for complex loads including a change in the microcracks status (for instance tension followed by compression). Moreover, the representation should be improved by the introduction of inelastic strain of the material induced by friction sliding still in micromechanical framework. Again, it will be interesting to account by this way of the interactions between closure effects, initial anisotropy and friction sliding and provide an enriched representation of the behavior of microcracked materials.

\section{Acknowledgments}

The authors would like to thank the F.R.S.-FNRS, the national funds of scientific research in Belgium, for their financial support in the FRFC project.

\section{Appendix A. Formulation of homogenized stiffness tensor chom}

According to Goidescu et al. [25], the homogenized stiffness tensor can be written as a function of the fabric tensor $\mathbf{A}$ and crack orientation $n^{r}$ as follows:

$$
\begin{aligned}
& {\left[2 \chi_{1}^{r} \mathbf{I} \otimes \mathbf{I}+2 \chi_{2}^{r} \mathbf{A} \otimes \mathbf{A}+\chi_{3}^{r}(\mathbf{I} \otimes \mathbf{A}+\mathbf{A} \otimes \mathbf{I})\right.} \\
& +2 \chi_{4}^{r} \underline{n}^{r} \otimes \underline{n}^{r} \otimes \underline{n}^{r} \otimes \underline{n}^{r} \\
& +\chi_{5}^{r}\left(\mathbf{I} \otimes \underline{n}^{r} \otimes \underline{n}^{r}+\underline{n}^{r} \otimes \underline{n}^{r} \otimes \mathbf{I}\right) \\
& +\chi_{6}^{r}\left(\underline{\mathbf{I} \otimes} \underline{n}^{r} \otimes \underline{n}^{r}+\underline{n}^{r} \otimes \underline{n}^{r} \underline{\otimes \mathbf{I}}\right) \\
& \mathbb{C}^{h o m}=\mathbb{C}^{s}+\sum_{r=1}^{N} d^{r} \mid \begin{array}{r}
+\frac{\chi_{7}^{r}}{2}\left[\left(\underline{n}^{r} \otimes \underline{n}^{r} \cdot \mathbf{A}+\mathbf{A} \cdot \underline{n}^{r} \otimes \underline{n}^{r}\right) \otimes \mathbf{I}\right. \\
\left.+\mathbf{I} \otimes\left(\underline{n^{r}} \otimes \underline{n}^{r} \cdot \mathbf{A}+\mathbf{A} \cdot \underline{n}^{r} \otimes \underline{n}^{r}\right)\right] \\
+\chi_{8}^{r}\left(\underline{n}^{r} \otimes \underline{n}^{r} \otimes \mathbf{A}+\mathbf{A} \otimes \underline{n}^{r} \otimes \underline{n}^{r}\right) \\
+\frac{\chi_{9}^{r}}{2}\left[\left(\underline{n}^{r} \otimes \underline{n^{r}} \cdot \mathbf{A}+\mathbf{A} \cdot \underline{n}^{r} \otimes \underline{n}^{r}\right) \otimes \mathbf{A}\right.
\end{array} \\
& \left.+\mathbf{A} \otimes\left(\underline{n}^{r} \otimes \underline{n}^{r} \cdot \overline{\mathbf{A}}+\mathbf{A} \cdot \underline{n}^{r} \otimes \underline{n}^{r}\right)\right] \\
& +\frac{\chi_{10}^{r}}{2}\left(\underline{n}^{r} \otimes \underline{n}^{r} \cdot \mathbf{A}+\mathbf{A} \cdot \underline{n}^{r} \otimes \underline{n}^{r}\right) \otimes \underline{n}^{r} \otimes \underline{n}^{r} \\
& \left.+\underline{n}^{r} \otimes \underline{n}^{r} \otimes\left(\underline{n}^{r} \otimes \underline{n}^{r} \cdot \mathbf{A}+\mathbf{A} \cdot \underline{n}^{r} \otimes \underline{n}^{r}\right)\right]
\end{aligned}
$$

in which the coefficients $\chi_{p}^{r}\left(\mathbb{C}^{s}, \underline{n}^{r}, \mathbf{A}\right)_{p=1,10}$ are given by Goidescu et al. [25] according to microcrack status (open or closed). From this formulation, interactions between anisotropies can be explicitly defined through combinations of $\mathbf{E}, \mathbf{A}$ and $n^{r} \otimes n^{r}$. Then, one could distinguish three kinds of coupling between the initial anisotropy and the microcracks induced one: (i) isotropic-like coupling thanks to terms of coefficients $\chi_{1}^{r}, \chi_{2}^{r}$ and $\chi_{3}^{r}$ that preserve the initial orthotropy of the material; (ii) weak anisotropic coupling thanks to terms of coefficients $\chi_{4}^{r}, \chi_{5}^{r}$ and $\chi_{6}^{r}$ that account for the loss of material orthotropy through tensorial terms identical to isotropy; primary anisotropy is only taken into account in constant $\chi_{4}^{r}, \chi_{5}^{r}$ and $\chi_{6}^{r}$ definitions; (iii) strong anisotropic coupling thanks to all other terms that introduce complex anisotropy through combinations of orientational effects of $n^{r}, \mathbf{A}$ and $\mathbf{E}$.

\section{References}

[1] Krajcinovic D. Damage mechanics. In: Achenbach JD, et al., editors. Applied mathematics and mechanics, vol. 41. Amsterdam: Elsevier Science Publishers B.V.; 1996.

[2] Lemaitre J, Chaboche J-L. Mechanics of solid materials. Cambridge: Cambridge University Press; 1990. 
[3] Budiansky B, O'Connell R. Elastic moduli of a cracked solid. Int J Solids Struct $1976 ; 12: 81-97$

[4] Horii H, Nemat-Nasser S. Overall moduli of solids with microcracks: loadinduced anisotropy. J Mech Phys Solids 1983;31:155-71.

[5] Zimmermann RW. Compressibility of sandstones. In: Chilingarian GV, editor Developments in petroleum science, vol. 29. Amsterdam, Elsevier: Elsevier Science Publishers B.V.; 1991.

[6] Kachanov M. Elastic solids with many cracks related problems. In: Hutchinson J, Wu T, editors. Advances in applied mechanics, vol. 30. New-York: Academic Press; 1993. p. 259-445.

[7] Andrieux S, Bamberger Y, Marigo J-J. Un modèle de matériaux microfissuré pour les roches et les bétons. J Méca Théor Appl 1986;5:471-513.

[8] Costanzo F, Boyd J, Allen D. Micromechanics and homogenization of inelastic composite materials with growing cracks. J Mech Phys Solids 1996:44:333-70.

[9] David EC, Brantut N, Schubnel A, Zimmerman RW. Sliding crack model for nonlinearity and hysteresis in the uniaxial stress-strain curve of rock. Int Rock Mech Min Sci 2012;52:9-17.

[10] Dormieux L, Kondo D. Stress-based estimates and bounds of effective elastic properties: the case of cracked media with unilateral effects. Comput Mater Sci 2009;46(1):173-9.

[11] Ju JW, Lee X. Micromechanical damage model for brittle solids. Part 1: tensile loading. Part 2: compressive loading. Mech Mater 1991:117(7):1495-536.

[12] Kachanov ML. A microcrack model of rock inelasticity. Part 1: frictional sliding on microcracks. Part 2: propagation of microcracks. Mech Mater 1982;1: $19-41$.

[13] Levasseur S, Collin F, Charlier R, Kondo D. A two scale anisotropic damage model accounting for initial stresses in microcracked materials. Eng Fract Mech 2011;78

[14] Levasseur S, Collin F, Charlier R, Kondo D. A micro-macro approach of permeability evolution in rocks excavation damaged zones. Comput Geotech 2013;49:245-52.

[15] Pensée V, Kondo D. Micromechanics of anisotropic brittle damage: comparative analysis between a stress based and a strain based formulation. Mech Mater 2003:35:747-61.

[16] Pensée V, Kondo D, Dormieux L. Micromechanical analysis of anisotropic damage in brittle materials. J Eng Mech 2002;128:889-97.

[17] Zhu QZ, Kondo D, Shao JF, Pensée V. Micromechanical coupling of anisotropic damage in brittle rocks and application. Int J Rock Mech Min Sci 2008;45: 467-77.

[18] Dragon A, Halm D. Damage Mechanics - Some modelling challenges. Polish Academy of Sciences. Warsaw: IPPT PAN; 2004.
[19] Dormieux L, Kondo D, Ulm F-J. Microporomechanics. Chichester: John Wiley \& Sons Ltd; 2006.

[20] Halm D, Dragon A, Charles Y. A modular damage model for quasi-brittle solids - interaction between initial and induced anisotropy. Arch Appl Mech 2002;72:498-510.

[21] Cazacu O, Soare S, Kondo D. On modeling the interaction between initial an damage-induced anisotropy in transversely isotropic solids. Math Mech Solids 2007;12(3):305-18.

[22] Chen L, Shao JF, Zhu QZ, Duveau G. Induced anisotropic damage and plasticity in initially anisotropic sedimentary rocks. Int J Rock Mech Min Sci 2012;51: 13-23.

[23] Baste S. Inelastic behaviour of ceramic-matrix composites. Compos Sci Technol 2001;61:2285-97.

24] Monchiet V, Gruescu C, Cazacu O, Kondo D. A micromechanical approach of crack-induced damage in orthotropic media: application to a brittle matrix composite. Eng Fract Mech 2012;83:40-53.

[25] Goidescu C, Welemane H, Kondo D, Cruescu C. Microcracks closure effects in initially orthotropic materials. Eur J Mech A/Solids 2013;37:172-84.

[26] Liao JJ, Yang MT, Hsien HY. Direct tensile behavior of a transversely isotropic rock. Int J Rock Mech Min Sci 1997;34(5):837-49.

[27] Marigo J-J. Modeling of brittle and fatigue damage for elastic material by growth of microvoids. Eng Fract Mech 1985;21(4):861-74.

28] Goidescu C. Caractérisation et modélisation de l'endommagement par microfissuration des composites stratifiés - Apports des mesures de champs et de l'homogénéisation [Ph.D. thesis]. Université de Toulouse; 2011.

[29] Pietruszczak S, Lydzba D, Shao JF. Modelling of inherent anisotropy in sedimentary rocks. Int J Solids Struct 2002;39:637-48.

[30] Cormery F, Welemane H. A stress-based macroscopic approach for microcracks unilateral effect. Comput Mater Sci 2010;47:727-38.

[31] Charlier R. Approche unifiée de quelques problèmes non linéaires de mécanique des milieux continus par la méthode des éléments finis (grandes déformations des métaux et des sols, contact unilatéral de solides, conduction thermique et écoulements en milieu poreux [Ph.D. thesis]. Université de Liège; 1987.

[32] Habraken AM. Contribution à la modélisation du formage des métaux par la méthodes des éléments finis [Ph.D. thesis]. Université de Liège; 1989.

[33] Hayes M. Connexions between the moduli for anistropic elastic materials. J Elast 1972;2(2):135-41.

[34] Ikogou S. Etude expérimentale et modélisation du comportement d'un grès. Ph.D. thesis. France: Université de Lille 1; 1990.

[35] Reinhardt HW. Fracture mechanics of elastic softening materials like concrete. Heron $1984 ; 29(2)$. 